\title{
LUDOWA RECEPCJA EWANGELICZNEJ PRZYPOWIEŚCI O DOBRYM PASTERZU W PRZEKAZACH PIEŚNI Z ŻYWEJ TRADYCJI CHRZEŚCIJANIE KATOLICY PROSZĘ POSEUCHAJCIE
}

Charakterystyczna postać wędrownego dziada wpisana jest w kulturę tradycyjną dawnej polskiej wsi. Dziadowie wędrowali od odpustu do odpustu, nawiedzali miejsca kultu pątniczego i lokalne kościoły, śpiewając pieśni religijne określane jako pieśni dziadowskie, za co otrzymywali jałmużnę ${ }^{1}$. Przyjmuje się, iż rozkwit bogatego repertuaru pieśni dziadowskich nastąpił w XVIII i XIX wieku. Popularyzowane przez dziadów, wraz z zanikiem ich funkcji w okresie międzywojennym, pieśni te zaadaptowały się w tradycji ludowej w licznych zwyczajach religijnych (pielgrzymki, pogrzeby, nabożeństwa przy kapliczkach i krzyżach) oraz w różnych świeckich praktykach okolicznościowych. Dzieła Wszystkie Oskara Kolberga, Karnawat dziadowski Stanisława Nyrkowskiego² czy Dziady. Rzecz o wędrownych żebrakach i ich pieśniach Piotra Grochowskiego ${ }^{3}$ nie zawierają zapisu pieśni dziadowskiej Chrześcijanie katolicy prosze postuchajcie. Nie oznacza to jednak jej małej powszechności czy nieznajomości, a może wynikać z wyboru do druku innych pieśni z tego gatunku.

Dr Kinga Strycharz-Bogacz - adiunkt w Instytucie Nauk o Sztuce Katolickiego Uniwersytetu Lubelskiego Jana Pawła II; e-mail: kingabogacz@wp.pl

Kinga Strycharz-Bogacz, PhD - The John Paul II Catholic University of Lublin; e-mail: kingabogacz@wp.pl

${ }^{1}$ M. DzIURA, Ludowe zwyczaje odpustowe, w: Chrześcijaństwo w religijności ludowej-1050 lat po Chrzcie Polski, red. Z. Kupisiński SVD, Lublin 2017, s. 131-132.

${ }^{2}$ Nyrkowski opublikował ok. 150 przekazów pieśni dziadowskich; zob. S. NyRKowsKi, Karnawat dziadowski. Pieśni wędrownych śpiewaków (XIX - XX w.), Warszawa 1973.

${ }^{3}$ Grochowski w swojej monografii opublikował teksty 58 pieśni dziadowskich z przełomu XIX i XX wieku; zob. P. Grochowski, Dziady. Rzecz o wędrownych żebrakach i ich pieśniach, Torun 2009. 
Pieśń Chrześcijanie katolicy proszę postuchajcie jest pieśnią dziadowską, której treść pośrednio dotyczy wydarzeń zbawczych i stanowi przykład ludowej recepcji ewangelicznej przypowieści o Dobrym Pasterzu. Ma ponad 50 zwrotek, których liczba zależy od zapisów rękopiśmiennych lub w drukach ulotnych, zaś jej strofy są 5-wersem heterosylabicznym o układzie $14+14+8+8+6$. Jest to przykład pieśni dziadowskiej alegorycznej, czyli jej tekst poza znaczeniem dosłownym posiada stały umowny sens przenośny. Treść pieśni opiera się na nowotestamentalnej przypowieści o Dobrym Pasterzu i zagubionej owcy (por. Mt 18,12-14). Posłużyła ona do zobrazowania pewnych tradycyjnie utrwalonych postaw i zachowań, które ludowy odbiorca rozumie jednoznacznie, zaś jej treść formuje ludowy system myślenia i wartości. Czytelne przesłanie zapowiada jej początek:

Chrześcijanie katolicy, proszę posłuchajcie

Co wam opowiadać będę, pilno pozór dajcie,

Byście dobrze zrozumieli,

a pożytek z tego mieli,

Dla duszy zbawienia.

Równie zrozumiałe jest końcowe wytłumaczenie alegorii:

Chrześcijanie czy wszystkoście dobrze zrozumieli,

Coście teraz w tej to pieśni ode mnie słyszeli

Owca jest każdy żyjący

Król jest sam Bóg wszechmogący.

Pasterz Jezus Chrystus.

On to pilno woła szuka owieczki zbłąkanej

Duszy człowieka grzesznego w świecie zatopionej,

By ją pozyskał dla siebie

I onę osadził w niebie

U Ojca swojego.

A gdyście tak zrozumieli, ze mną zaśpiewajcie,

A ze serca pokornego do Boga wołajcie,

Jak bardzo nas umiłował

Kiedy dla mnie nie żałował

Syna jedynego.

Ale go wydał tak na śmierć, dla ludu grzesznego

Aby którzy się nawrócą i uwierzą w niego:

Żeby wiecznie nie zginęli,

Lecz przez niego osiągnęli

Raj i żywot wieczny. Amen ${ }^{4}$.

\footnotetext{
${ }^{4}$ Tekst pochodzi z druku ulotnego z AMFR IM KUL (Du7).
} 
Materiał muzyczny, wybrany do przedstawienia podjętego tematu, pochodzi z Archiwum Muzycznego Folkloru Religijnego (AMFR) przy Katedrze Etnomuzykologii i Hymnologii KUL. Obejmuje on 55 nagranych przekazów pieśni Chrześcijanie katolicy proszę postuchajcie z 13 regionów Polski. Należy podkreślić, iż ludowa recepcja ewangelicznej przypowieści o Dobrym Pasterzu jest niezwykle inspirująca, gdyż w zebranym zbiorze odnotowujemy aż 11 różnych wersji melodycznych tej pieśni. Wśród nich mamy 6 wersji jako pojedyncze przekazy oraz 5 wersji w wielu przekazach zwariabilowanych, zaś warianty te są bliższe, dalsze i bardzo odległe. Również tekst w 55 nagraniach tej pieśni wykazuje wariantywność, co wynika z jego ustnego przekazu. Różnice w poszczególnych przekazach pieśni widoczne są już $\mathrm{w}$ treści początkowych zwrotek, np. pilnie pozór dajcie pilnie uważajcie; po śmierci zbawienie - dla duszy zbawienie, ujrzat ślicznego młodzieńca - $i$ napotkat on młodzieńca. Niektóre przekazy mają cechy gwarowe, np. opowiadać beda (Okrzeja), byście dobrze zrozumnieli, a pożytek z tego mnieli (Łyse), dlja duszy (Hyżne, Okrzeja), do Jeruzalim, z żalim (Gidle), ‘ojciec, 'bwiec, (Głogów).

W związku z podjętym tematem należy odnieść się do nowatorskiej koncepcji badawczej Bolesława Bartkowskiego. Dokonał on systematyzacji ludowych śpiewów religijnych w oparciu o istotne kryterium funkcji, którą określa czas i miejsce ich wykonania oraz rodzaj ich związku z obrzędem ${ }^{5}$. Chrześcijanie katolicy prosze postuchajcie należy do gatunku pieśni dziadowskich, niemniej wśród jej 55 nagrań odnotowujemy ciekawe zjawisko wielofunkcyjności, gdyż lud określa ją jako: pieśń pogrzebową, pieśń na „puste noce”, pieśń wielkopostną - na Wielką Sobotę, pieśń do Pana Jezusa, pieśń pielgrzymkową i odpustową, pątniczą, pieśń przygodną oraz pieśń śpiewaną w maju przy kapliczkach. Zatem alegoryczna przypowieść o Dobrym Pasterzu, który w trosce o swoje owce oddaje za nie życie, stanowi stałą treść pieśni, ale zmienia się funkcja pieśni.

Jak słusznie zauważa Piotr Dahlig, śpiewacy ludowi uważają każde wykonanie zarówno za wzór dla późniejszych wykonań, jak również za niepowtarzalną indywidualną prezentację ${ }^{6}$ To właśnie warunkuje powstawanie licznych wariantów pieśni oraz nowych wersji istniejących już pieśni. W przypadku badanej pieśni mamy, jak już wspomniano, 6 wersji jako pojedyncze przekazy oraz 5 wersji w bardzo wielu przekazach zwariabilowanych.

${ }^{5}$ A. ZoŁA, Koncepcja badań nad żywa tradycja polskich śpiewów religijnych w ujęciu Bolesława Bartkowskiego, „Additamenta Musicologica Lublinensia” 4(2008), z. 1, s. 16-17.

${ }^{6}$ P. DAhlig, Muzyka ludowa we współczesnym społeczeństwie, Warszawa 1987, s. 18. 


\section{Wersja I}

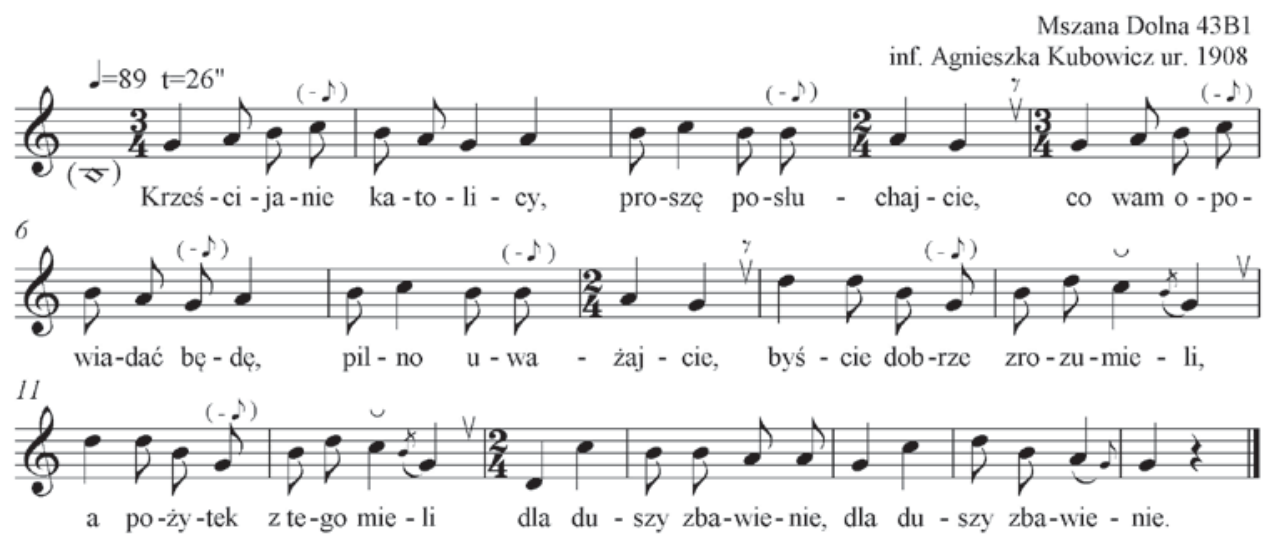

Melodia I wersji pieśni z Mszany Dolnej w Małopolsce ma szeroki ambitus oktawy $^{7}$ i charakter falisty, a rozwija się płynnym ruchem sekundowo-tercjowym i po dźwiękach trójdźwięku. Pojawiają się zdobienia w postaci przednutek i ponutki. Interwały charakterystyczne (kwarta w dół oraz septyma i kwarta w górę) występują na końcach i na początku motywów. Informatorka świadomie myśli frazą muzyczną - stąd prowadzi melodię ze swobodą metrorytmiczną. Powoduje to zmienność metrum (naprzemiennie 3/4 i 2/4) oraz częste skracanie wartości rytmicznych. Pieśń ma formę 2-częściową ${ }^{8}$ typu AB o wewnętrznej strukturze aabc. Ta wersja pieśni funkcjonuje tylko w Mszanie Dolnej, nie jest jednak pewne, czy również stamtąd pochodzi. Wprawdzie informatorka Agnieszka Kubowicz uczyła się śpiewać w domu, ale bardzo często jeździła na Kalwarię, gdzie stykała się z repertuarem z całej Polski, a mając znakomitą pamięć, po jednokrotnym usłyszeniu danej pieśni, potrafiła ją zapamiętać i włączała do swojego repertuaru. W ten sposób mogły w nim znaleźć się melodie z innych regionów, które informatorka zaadaptowała do lokalnej tradycji śpiewu, dodając też indywidualne cechy wykonawcze.

${ }^{7}$ A. ZoŁa, Melodyka ludowych śpiewów religijnych $w$ Polsce, Lublin 2003, s. 177.

${ }^{8}$ B. Bartkowski, Polskie śpiewy religijne $w$ żywej tradycji. Style i formy, Kraków 1987, s. 157 . 


\section{Wersja II}
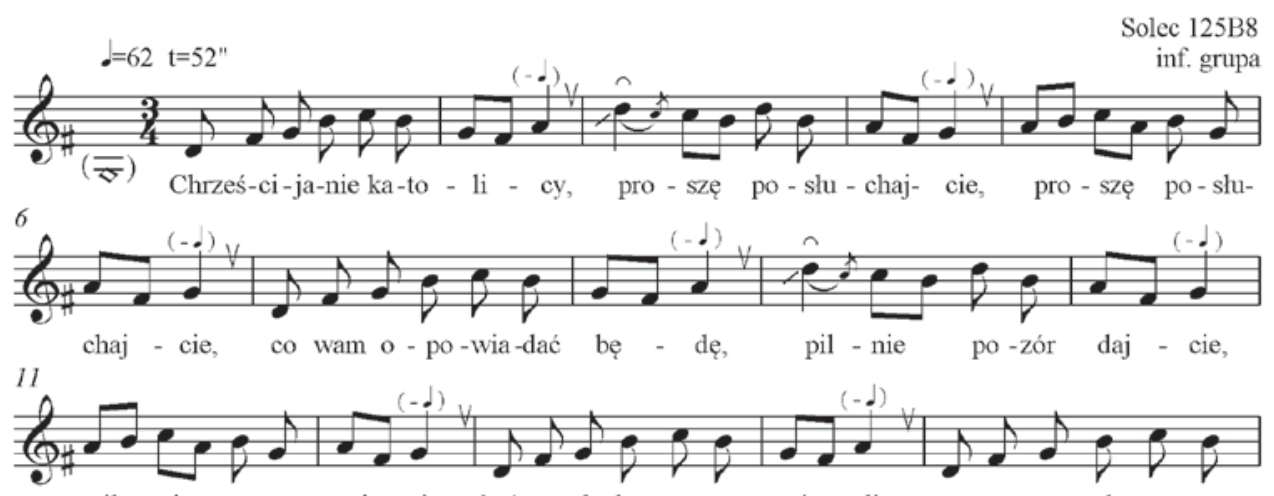

pil - nie u - wa - żaj - cie, byś-my do-brze zro-zu - mie - li, a po - ży - tek zte - go

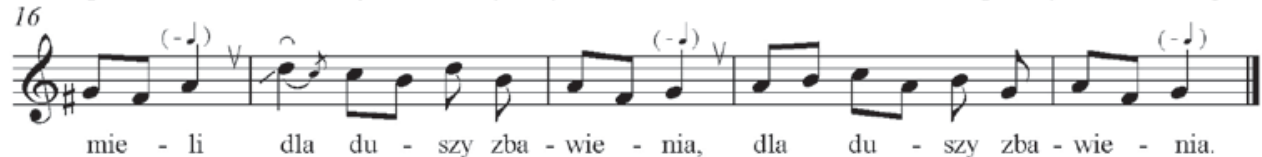

II wersja z Solca na Mazowszu ma szeroki ambitus oktawy i przebiega w warstwie melodycznej ruchem tercjowo-sekundowym. Opiera się na 3 frazach melodycznych, z których każda ma inny kierunek (wznoszący, opadający, falisty). W toku sylabicznym 19-krotnie pojawiają się 2-nutowe melizmy. Mimo że cała melodia jest w stałym metrum 3/4, co 2 takty skracana jest o połowę ostatnia wartość oraz wydłużane jest trwanie wszystkich 3 punktów kulminacyjnych melodii, co w pewnym stopniu zaburza płynny przebieg trójmiaru, a świadczy o naturalnym myśleniu frazą muzyczną. Złożona budowa formalna wynika z powtórzeń tekstu $\mathrm{z}$ nową melodią; ma ona postać 3-częściową ${ }^{9} \mathrm{AAB}$ o wewnętrznym wieloczłonowym układzie (abc abc aabc).

${ }^{9}$ B. BartKowski, Polskie śpiewy, s. 176. 


\section{Wersja III}

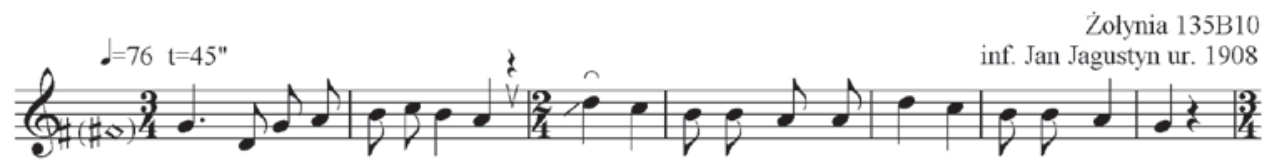

Chrześ-ci-ja-nie ka-to-li-cy, pro-szę po-shu-chaj-cie, pro-szę po-słu-chaj-cie,

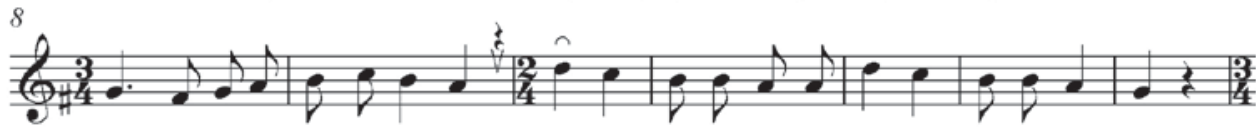

co wam o-po - wia-dać bę- dę, pil-nie po-zór daj-cie, pil-nie po-zór daj - cie,

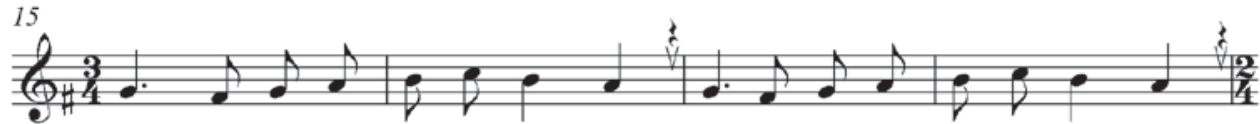

byś - cie dob-rze u - sly-sze - li, a po-ży - tek zte - go mie - li

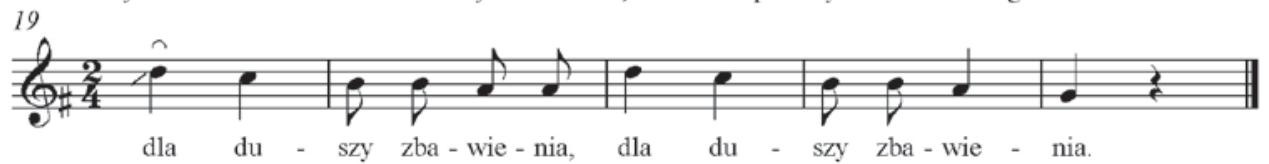

III wersja (z Żołyni na Podkarpaciu) o szerokim ambitusie oktawy opiera się na płynnym ruchu sekundowym i wykorzystuje 2 frazy melodyczno-rytmiczne o znaczeniu formotwórczym. Wykazują one skontrastowanie w przebiegu pod względem kierunku linii melodycznej (falisty i opadający) oraz utrzymane są w zmiennym metrum 3/4 i 2/4. Budowa formalna jest 3-częściowa o członach podobnych typu $\mathrm{AA}_{1} \mathrm{~A}_{2}$. Uwagę zwraca tok w pełni sylabiczny.

\section{Wersja IV}

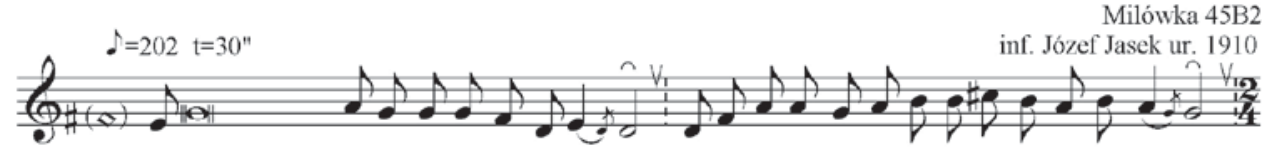

Chrześ-ci-ja-nie ka-to-li-cy pro szę po-sluchaj-cie, co wamo-po-wiadać bę-dę pil-no po-zór daj-cie,

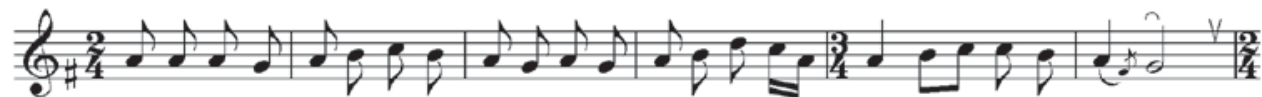

byś-ciedob-rze zro-zu-mie-li, a po-žy-tek zte-gomie-li dla du - szy zba-wie-nia,

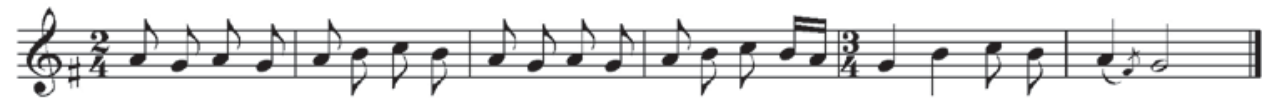

byś-cie dob-rze zro-zu-mie-li, a po-ży-tek zte-go mie-li dla du-szy zba - wie-nia.

IV wersję pieśni (przekaz z Milówki na Żywiecczyźnie) o szerokozakresowej melodii cechuje dwufazowość. Pierwsza faza, bezmetryczna i o charakterze psal- 
modycznym, zawiera charakterystyczną dla skali górali żywieckich lidyzację, czyli podwyższenie IV stopnia. Natomiast druga faza, w zmiennym metrum 2/4 i 3/4, rozwija się płynnym ruchem sekundowym w wąskim zakresie kwinty, co może świadczyć o jej archaicznym pochodzeniu. W tej wersji dominuje ruch ósemkowy, a forma jest 3-częściowa o członach różnych typu ABB (ab cd cd). Zdobienia melodii obejmują tylko ponutki, występujące wyłącznie na zakończenie poszczególnych fraz tekstu, co może wynikać z indywidualnej maniery wokalnej informatora Józefa Jaska z Milówki, bardzo zacnego wieloletniego przewodnika odpustowego, kalwaryjskiego i pogrzebowego. Owa oryginalna wersja pieśni stanowi niewątpliwie swoiste połączenie rdzennej lokalnej tradycji śpiewów z możliwymi wpływami melodii z innych regionów, zasłyszanymi podczas licznych pielgrzymek informatora, a cały przebieg jest niejako „przefiltrowany” przez subiektywną wrażliwość muzyczną wykonawcy.

\section{Wersja V}
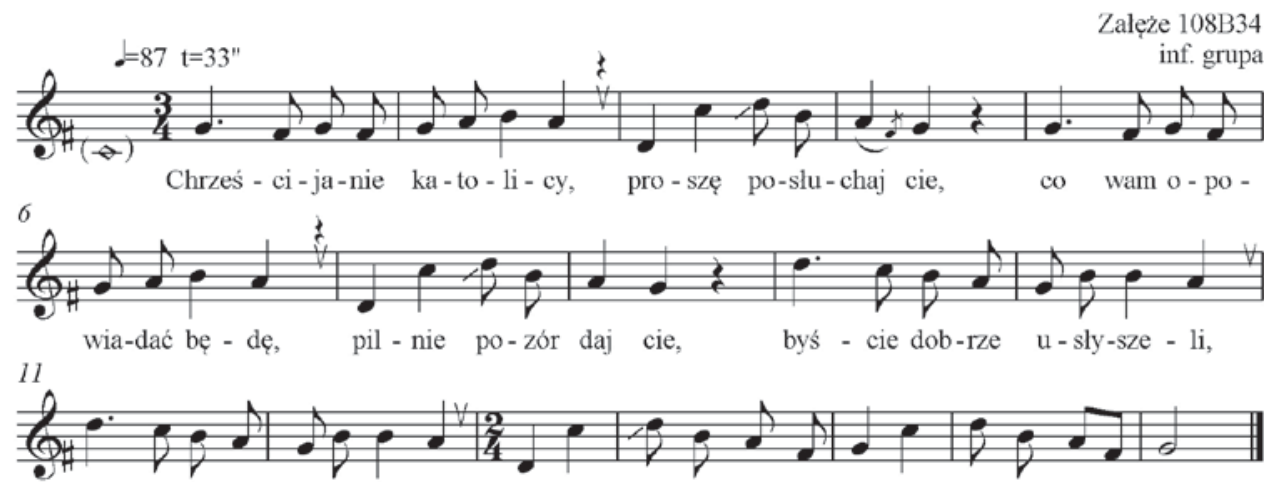

a po-ży-tek zte-go mie-li dla du - szy zba-wie-nia, dla du - szy zba-wie - nia.

Melodia V wersji pieśni (z Załęża na Podkarpaciu) o szerokim ambitusie oktawy przebiega płynnym ruchem sekundowo-tercjowym w oparciu o 3 frazy o falistym kształcie. Charakterystyczne skoki obejmują interwał septymy małej i kwarty w górę. Metrum trójdzielne jest dwukrotnie zakłócone przez dodanie pauzy oddechowej o długości ćwierćnuty, niemniej zmienia się ono w ostatnim wersie tekstu na metrum dwudzielne. Drobne glissando wokalne antycypuje powtarzający się punkt kulminacyjny melodii. Dominuje tok sylabiczny, jedynie w kadencji pojawia się 2-nutowa melizma. Forma jest 4-częściowa ${ }^{10}$ o członach różnych typu $\mathrm{AABA}_{1}$ $\left(a b a b c c b_{1} b_{2}\right)$.

${ }^{10}$ B. BartKowski, Polskie śpiewy, s. 184-188. 


\section{Wersja VI}

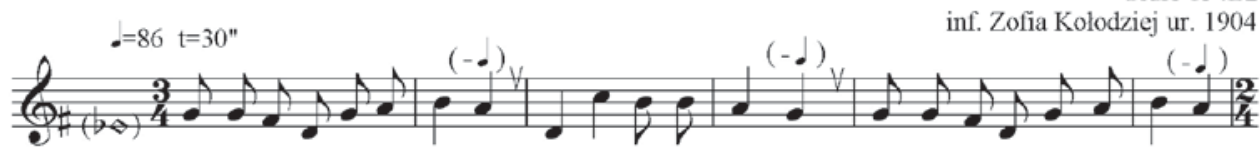

Chrześ-ci-ja-nie ka-to - li-cy, pro-szę po-slu-chaj-cie, co wam o-po-wia-dal bę-dę,

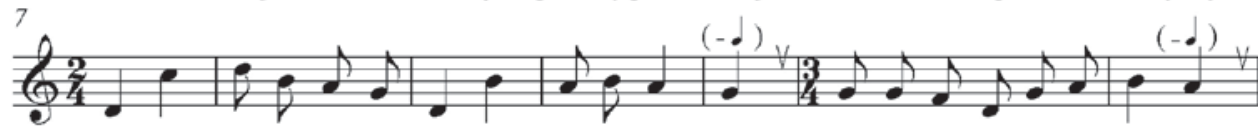

pil-nie po-zór daj-cie, pil-nie po-zór daj - cie, byś-cie dob-rze zro-zu - mie - li

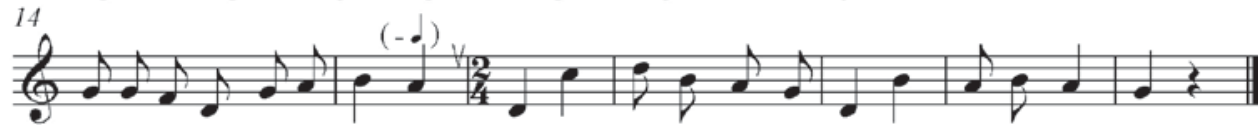

i po-ży-tek zte-go mie - li dla du - szy zba-wie-nia, dla du - szy zba-wie - nia.

Przekaz pieśni z parafii Gidle (Polska centralna), czyli VI wersja pieśni, posiada melodię o szerokim zakresie oktawy i kształcie falistym, w której występują skoki interwałowe w górę septymy małej, seksty wielkiej oraz kwarty. Metrum jest zmienne: $3 / 4$ i 2/4, naprzemiennie występują ugrupowania ósemkowe i ćwierćnutowe, co decyduje o swoistej pulsacji całego przebiegu melodii. Uwagę zwracają odcinki utrzymane w trójmiarze, które zawsze pozbawione są jednej wartości metrycznej na końcu wersu. Ciekawa jest rozbudowana, lecz jednorodna forma złożona z 4 członów podobnych typu $\mathrm{AA}_{1} \mathrm{~A}_{2} \mathrm{~A}_{3}$.

\section{Wersja VII}

Sztum 29A2

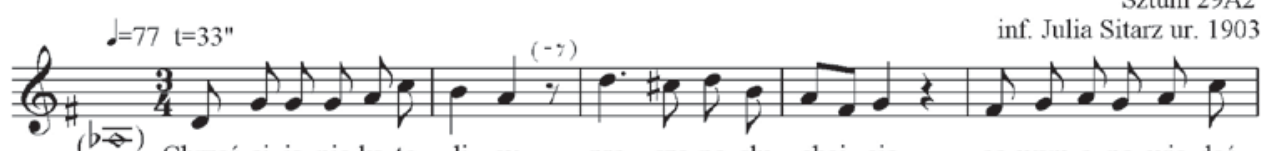

Chrześ ci-ja-nie ka-to - li - cy, pro - szę po-shu- chaj-cie,

co wam o-po-wia-dać

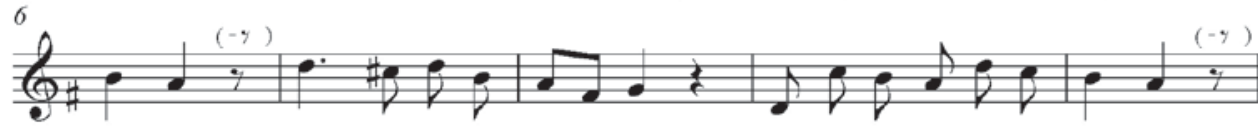

bę - dę, pil - nie po zór daj - cie, byś - cie do-brze zro-zu - mie - li

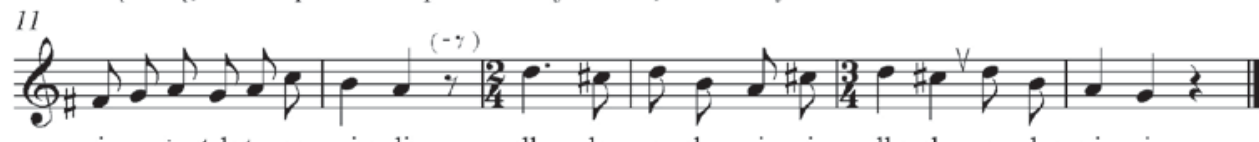

i po-ży-tek te-go mie-li dla du-szy zba-wie-nia, dla du-szy zba-wie-nia. 
VII wersja pieśni ma 3 warianty z różnych regionów Polski (Podkarpacie i Pomorze). Ich szerokozakresowe melodie przebiegają płynnym ruchem sekundowo-tercjowym w metrum zmiennym i mają tok sylabiczny z pojedynczymi 2-nutowymi melizmami. Charakterystyczne interwały stanowią subkwarta inicjująca wszystkie warianty oraz septyma mała w górę w 2 wariancie o najbardziej ruchliwej i urozmaiconej melodii. Cechą indywidualizującą warianty 2 i 3 jest równorzędne występowanie dźwięków $c^{2}$ oraz $c i s^{2}$, co świadczy o lidyzacji melodii. Mimo pokrewieństwa, każdy wariant posiada inną formę 4-częściową typu $\mathrm{AA}_{1} \mathrm{~A}_{2} \mathrm{~A}_{3}, \mathrm{AA}_{1} \mathrm{BA}_{2}$ i $\mathrm{AABA}_{1}$.

\section{Wersja VIII}
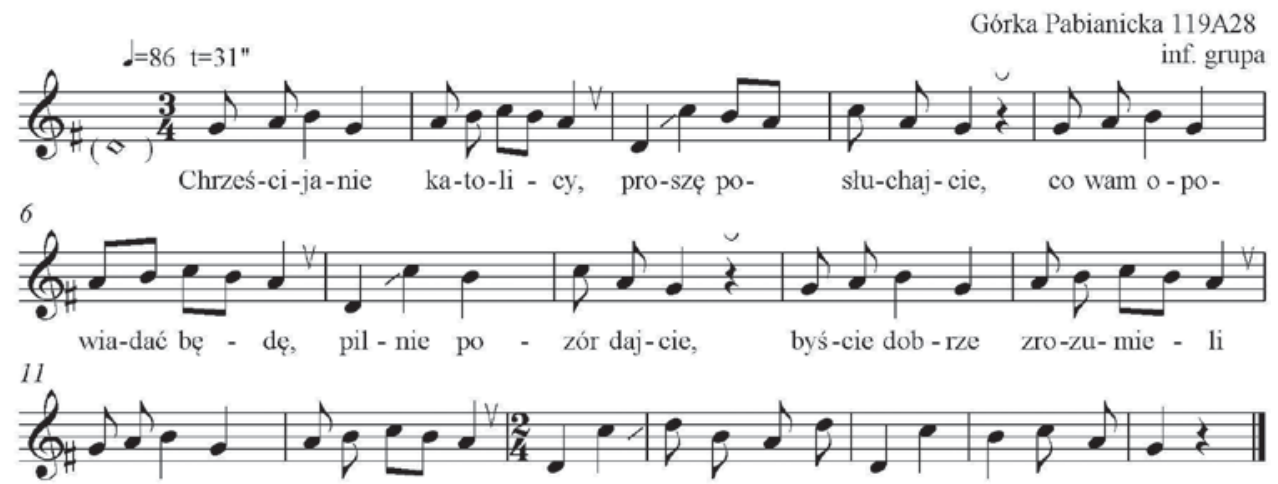

a po-ży-tek zte-go mie - li dla du - szy zba-wie-nia, dla du - szy zba-wie-nia.

VIII wersja również ma 3 warianty z różnych regionów Polski (Podkarpacie, Kurpie, Polska centralna). Szerokozakresowe warianty 1 i 3 mają zmienne metrum, zaś średniozakresowy ${ }^{11}$ wariant 2 o ambitusie septymy posiada stałe metrum. Wszystkie warianty wykazują zróżnicowanie w prowadzeniu linii melodycznej poszczególnych fraz oraz inne rozłożenie przebiegu melodii w taktach wskutek odmiennych ugrupowań rytmicznych. W 2 wariancie, o toku w pełni sylabicznym, dźwięki repetycyjne mają funkcję formotwórczą, zaś w 3 wariancie formotwórcza jest progresja motywiczna. Mimo różnic, warianty posiadają identyczną formę 4-częściową typu $\mathrm{AAA}_{1} \mathrm{~B}$ z drobnymi różnicami członów składowych.

${ }^{11}$ A. ZoŁA, Melodyka, s. 144. 


\section{Wersja IX}

Skrzvńsko 2A27

. $=81 \quad \mathrm{t}=32$

inf. Jan Bilski ur. 1914

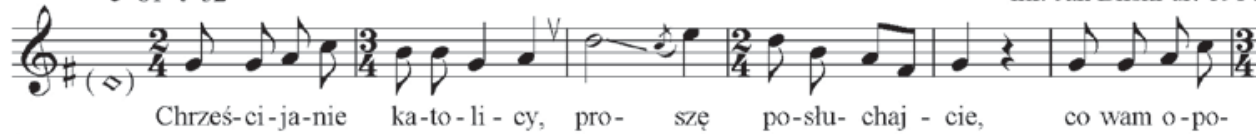

7

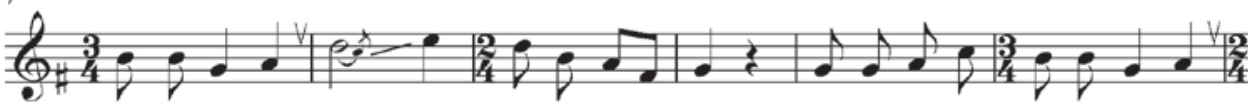

wia-dać bę-dę pil - no po-zór daj - cie, byś-cie dob-rze zro-zu-mie-li,

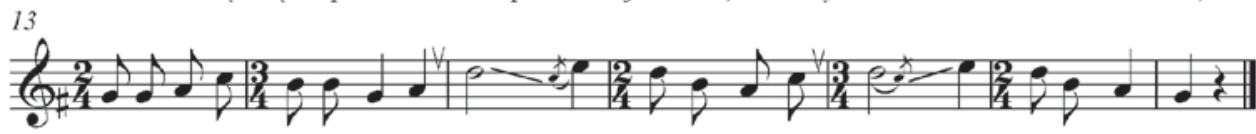

a po-ży-tek zte-go mie-li dla du - szy zba-wie-nia, dla du - szy zba-wie-nia.

IX wersja pieśni obejmuje 4 warianty z 3 regionów: Mazowsze, Świętokrzyskie, Polska centralna. Jej średniozakresowa melodia rozwija się ruchem sekundowo-tercjowym w oparciu o 2 frazy melodyczno-rytmiczne i ma zmienne metrum. W płynnym przebiegu ósemkowo-ćwierćnutowym wyróżniają się półnuty poprzedzające punkt kulminacyjny osiągnięty przez glissando wokalne. Forma jest jednorodna 4-częściowa typu $\mathrm{AAA}_{1} \mathrm{~A}_{2}$. W przekazie ze Skrzyńska (Mazowsze) odnotowujemy zjawisko wariabilności międzystroficznej, czyli zmiany melodyczno-rytmiczne pomiędzy zwrotkami. Pozostałe 3 warianty mają nieco inny układ melodii w kolejnych taktach. Uwagę zwraca bardzo nietypowa inicjacja 1 frazy od VII stopnia skali, czyli dźwięku fisl (wariant z Mirca w Świętokrzyskiem). Te 3 warianty wykazują zmiany wysokości i wartości pojedynczych nut oraz nie posiadają powtórzenia ostatniego wersu, stąd skróceniu ulega ich forma, zatem w tej wersji zachodzi zjawisko wariabilności melodyczno-rytmiczno-formalnej.

\section{Wersja X}

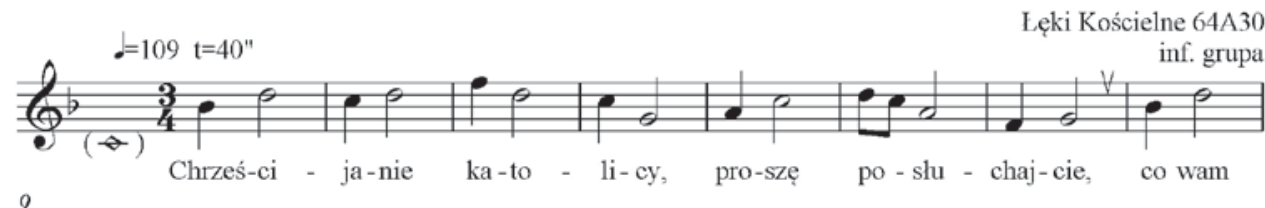

9

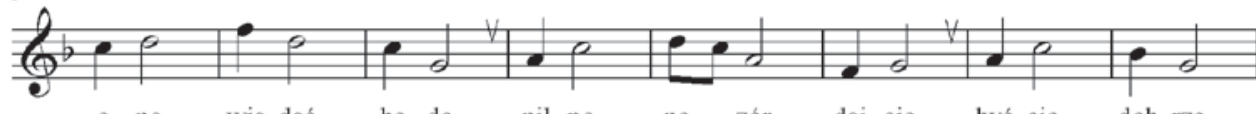

o-po - wia-dać bẹ-dę, pil-no po- zór daj-cie, byś-cie dob-rze

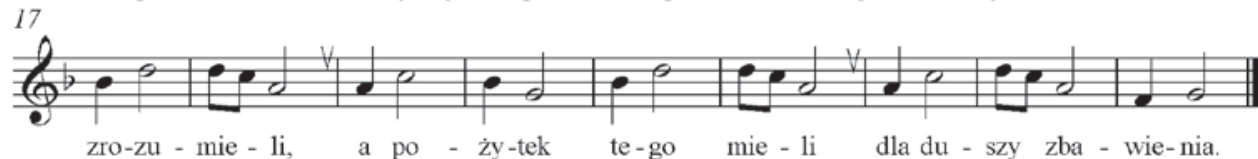


Melodia wszystkich dziesięciu przekazów X wersji pieśni (z 3 regionów: Mazowsze, Kujawy, Polska centralna) rozwija się ruchem tercjowo-sekundowym z wykorzystaniem charakterystycznego skoku o interwał kwarty w dół. Przeważa tok sylabiczny, sporadycznie pojawiają się 2-nutowe melizmy oraz glissando wokalne. Zjawisko wariabilności obejmuje wszystkie melodie tej wersji, śpiewane w tempie umiarkowanym (5 przekazów) i szybkim (5 przekazów). Ma tu miejsce swoista wariabilność agogiczna pomiędzy przekazami z Mazowsza z miejscowości położonych zaledwie $8 \mathrm{~km}$ od siebie; w parafii Płock-Radziwie śpiewa się w tempie umiarkowanym, a w parafii Dobrzyków - w tempie szybkim. Jest to przykład typowo ludowej odmienności przekazów bliskich geograficznie, gdyż sąsiedztwo nie gwarantuje identyczności śpiewu. W jednym $\mathrm{z}$ wariantów odnotowujemy melodię opartą o heptachord dorycki $\mathrm{e}^{2}-\mathrm{d}^{2}-\mathrm{c}^{2}-\mathrm{b}^{1}-\mathrm{a}^{1}-\mathrm{g}^{\mathrm{l}}$. Natomiast w przekazach pieśni z parafii w Polsce centralnej i Kujaw występuje charakterystyczny brak dźwięku prowadzącego fis; zamiast niego występuje dźwięk $f$ jako obniżenie VII stopnia, co określamy jako miksolidyzm ${ }^{12}$. Jest to nawiązanie do modalności i potwierdza archaiczny sposób myślenia wokalnego. Potwierdza to także przekaz ze Złakowa Kościelnego (Mazowsze), gdzie na czterech sylabach słowa „ka-to-li-cy” śpiewane są 2-nutowe melizmy po dźwiękach $\mathrm{f}^{2}-\mathrm{e}^{2}-\mathrm{d}^{2}-\mathrm{c}^{2}-\mathrm{b}^{1}-\mathrm{a}^{1}-\mathrm{g}^{1}$ prezentujące wspomnianą skalę miksolidyjską. Trzeba zauważyć, że wersja $\mathrm{X}$ jest jedyną utrzymaną w trybie mollowym i jako taka funkcjonuje jako pieśń pogrzebowa bądź pieśń na „puste noce”, także ze wskazaniem do śpiewu u młodego nieboszczyka naprzemiennie przez mężczyzn i kobiety w bardzo wysokim rejestrze (Złaków Kościelny). Wyjątkowo szeroka funkcja tej wersji pieśni występuje w miejscowości Kawenczyn (Mazowsze). Zgodnie z lokalną tradycją śpiewano ją dawniej przy krzyżu, w wolnych chwilach oraz przy wystawieniu Najświętszego Sakramentu i innych okazjach. Ta wielość funkcji świadczy o wyjątkowym upodobaniu przekazu treści tej pieśni przez tamtejszych parafian.

${ }^{12}$ A. Zota, Gregorian chant and folk culture in Poland, w: Traditional musical cultures in Central-Eastern Europe. Ecclesiastical and folk transmission, red. P. Dahlig, Warszawa 2009, s. 255. 


\section{Wersja XI}

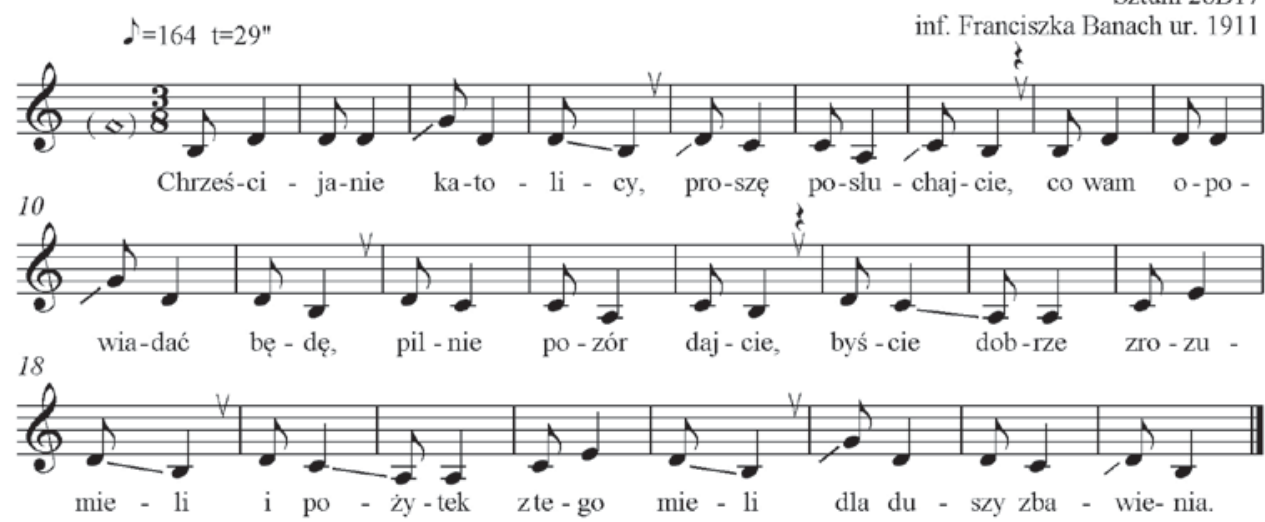

Wersja XI reprezentowana jest przez 29 przekazów z 8 regionów (Mazowsze, Wielkopolska, Lubelszczyzna, Mazury, Podlasie, Dolny Śląsk, Pomorze, Polska centralna), zatem nieco ponad połowa nagrań tej pieśni stanowi warianty jednej wersji melodycznej, z czego 23 przekazy są w tempie szybkim, zaś 6 przekazów w tempie umiarkowanym. Znamienne jest to, iż ta wersja melodyczna wykorzystuje jako podstawę rytmiki całej pieśni jambiczną formułę rytmiczną, czyli układ typu krótka i długa wartość na dwóch sylabach w takcie, co jest charakterystyczne dla gatunku pieśni narracyjnych ${ }^{13}$, podobnie jak w przypadku omówionej $\mathrm{X}$ wersji tej pieśni. Warianty z parafii Gradzanowo (Mazowsze) i Łęki Kościelne (Polska centralna) wykazują lidyzację $\left(c i s^{2}\right)$, przy równoczesnym występowaniu dźwięku $c^{2}$ w melodii, co można uznać za dość nietypowe zjawisko na tym terenie, gdyż funkcjonuje ono zwykle na obszarach górskich. Często pojawia się glissando wokalne; zwykle wypełnia ono interwał tercji oraz poprzedza poszczególne dźwięki melodii. Występują także drobne zdobienia melodii w postaci ponutek oraz 2-nutowe melizmy. Odnotowujemy odmienne tempo wykonania pieśni przez solistę i przez grupę. Forma XI wersji jest 3-częściowa $\mathrm{ABa}_{1}$.

${ }^{13}$ B. BARTKOWSKI, Uwagi o polskich religijnych pieśniach narracyjnych, „Roczniki Teologiczno-Kanoniczne" 34(1987), z. 7, s. 86. 
Przeprowadzone badania wykazały, iż ludowa recepcja przypowieści o Dobrym Pasterzu w przekazach pieśni Chrześcijanie katolicy prosze postuchajcie zaowocowała ich wyjątkowym bogactwem jakościowym i ilościowym, a wśród zgromadzonych 55 nagrań tej pieśni z 13 regionów Polski nie ma dwóch identycznych. Ta genetycznie ludowa pieśń jest znakomitym przykładem szeroko pojętego zjawiska wariabilności, reprezentowanej tutaj przez ciekawe warianty i wersje melodyczne. W badanym repertuarze funkcjonują różne bliższe i dalsze warianty melodyczno-rytmiczne, formalne (forma 2-, 3- i 4-częściowa), agogiczne (tempo umiarkowane i szybkie) oraz tekstowe, pojawia się też wariabilność międzystroficzna poszczególnych przekazów. Występują różne wersje jednej pieśni na terenie danej parafii. Ta wielopłaszczyznowa wariabilność przekazów powoduje ogromne bogactwo przekształceń będących nośnikiem nowych jakości. W warstwie melodyczno-tonalnej dominuje system dur-moll, ale słyszalne są też wyraźne odniesienia do skal modalnych. Na uwagę zasługuje wielofunkcyjność tej pieśni. Jest ona niewątpliwie potwierdzeniem szczególnej wymowy przypowieści o Dobrym Pasterzu, która przybierając formę pieśni stanowi piękny przykład praktykowania pobożności ludowej, czyli autentycznego przeżywania religijności, zarówno w kościele, jak i poza kościołem.

\section{BIBLIOGRAFIA}

BARTKOWSKi B., Uwagi o polskich religijnych pieśniach narracyjnych, „Roczniki Teologiczno-Kanoniczne" 34(1987), z. 7, s. 81-88.

BartKowski B., Polskie śpiewy religijne w żywej tradycji. Style i formy, Kraków 1987.

DAHLIG P., Muzyka ludowa we współczesnym społeczeństwie, Warszawa 1987.

Dziura M., Ludowe zwyczaje odpustowe, w: Chrześcijaństwo w religijności ludowej - 1050 lat po Chrzcie Polski, red. Z. Kupisiński SVD, Lublin 2017, s. 117-135.

Grochowski P., Dziady. Rzecz o wędrownych żebrakach i ich pieśniach, Toruń 2009.

Nyrkowski S., Karnawat dziadowski. Pieśni wędrownych śpiewaków (XIX-XX w.), Warszawa 1973. ZoŁa A., Gregorian chant and folk culture in Poland, w: Traditional musical cultures in Central-Eastern Europe. Ecclesiastical and folk transmission, red. P. Dahlig, Warszawa 2009, s. 243-256.

ZoŁa A., Koncepcja badań nad żywą tradycja polskich śpiewów religijnych w ujęciu Bolesława Bartkowskiego, „Additamenta Musicologica Lublinensia” 4(2008), z. 1, s. 11-18.

ZoŁA A., Melodyka ludowych śpiewów religijnych w Polsce, Lublin 2003. 


\section{LUDOWA RECEPCJA EWANGELICZNEJ PRZYPOWIEŚCI O DOBRYM PASTERZU \\ W PRZEKAZACH PIEŚNI Z ŻYWEJ TRADYCJI CHRZEŚCIJANIE KATOLICY PROSZĘ POSEUCHAJCIE}

Streszczenie

Artykuł ma na celu przedstawienie ludowej recepcji nowotestamentalnej przypowieści o Dobrym Pasterzu w przekazach pieśni Chrześcijanie katolicy proszę posłuchajcie. Należy ona do gatunku pieśni dziadowskich i w zebranym materiale empirycznym reprezentowana jest przez 55 nagrań pochodzących z 13 regionów Polski. Badania ukazały wyjątkowo wysoki stopień wariabilności warstwy muzycznej oraz wariantywność tekstu tej pieśni. Niewątpliwie decyduje o tym jej genetycznie ludowe pochodzenie. Dzięki temu pieśń ta funkcjonuje w 11 różnych wersjach melodycznych oraz licznych wariantach melodycznych, rytmicznych, formalnych, agogicznych i międzystroficznych, które również wykazują regionalne, subregionalne czy lokalne uwarunkowania.

Słowa kluczowe: pieśni dziadowskie; ludowa recepcja treści biblijnych; wariabilność.

\section{FOLK RECEPTION OF THE EVANGELICAL PARABLE ABOUT THE GOOD SHEPHERD IN THE RECORDINGS OF THE RELIGIOUS SONG CHRZEŚCIJANIE KATOLICY PROSZĘ POSEUCHAJCIE (CHRISTIAN CATHOLICS PLEASE LISTEN)}

\section{Sum mary}

The article aims to show the folk reception of the New Testament parable about the Good Shepherd in the religious song Chrześcijanie katolicy prosze postuchajcie (Christian Catholics please listen). It belongs to the genre of beggar's songs and is represented in the collected empirical material by 55 recordings from 13 Polish regions. The research proved an exceptionally high degree of variability of the musical layer and variants of the lyrics of this song. Undoubtedly, it is determined by its genetically folk origin. Thanks to this, the song functions in 11 different melodic versions as well as numerous melodic, rhythmic, formal, agogic and interstrophic variants which also show regional, subregional or local determinants.

Key words: beggar's songs; folk reception of biblical content; variability. 